\title{
Effects of origin, seasons and storage under different temperatures on germination of Senecio vulgaris (Asteraceae) seeds
}

\author{
Noel Ndihokubwayo ${ }^{1,2}$, Viet - Thang Nguyen ${ }^{1,3}$, Dandan Cheng Corresp. 4 \\ ${ }^{1}$ School of Environmental Studies, China University of Geosciences (Wuhan), Wuhan, China \\ 2 Département des Sciences Naturelles,, Ecole Normale Supérieure, Bujumbura, Burundi \\ 3 Faculity of Biology, Thai Nguyen University of Education, Thai Nguyen City, Vietnam \\ ${ }^{4}$ State Key Laboratory of Biogeology and Environmental Geology, China University of Geosciences (Wuhan), Wuhan, China \\ Corresponding Author: Dandan Cheng \\ Email address: dandan.cheng@cug.edu.cn
}

Invasive plants colonize new environments, become pests and cause biodiversity loss, economic loss and health damage. Senecio vulgaris L. (Common groundsel, Asteraceae), a cosmopolitan weed wildly distributes in the temperate area, is reported with large populations in the north-eastern and south-western part, but not in southern, central, or north-western part of China. We studied the germination behavior of $S$. vulgaris to explain the distribution and the biological invasion of this species in China. We used seeds originating from 6 native and 6 invasive populations to conduct germination experiments in a climate chamber and under outdoor condition. When incubated in a climate chamber $\left(15^{\circ} \mathrm{C}\right)$ seeds from majority of the populations showed $>90 \%$ germination percentage (GP) and the GP was equal for seeds with native and invasive origin. The mean germination time (MGT) was significant different among the populations. Under outdoor conditions, significant effect of origin, storage conditions (stored at $4{ }^{\circ} \mathrm{C}$ or ambient room temperature, ca. $27^{\circ} \mathrm{C}$ ) and seasons (in summer or autumn) were observed on the GP while the MGT was only affected by the season. In autumn, the GP (38.6\%) was higher and the MGT was slightly longer than that in summer. In autumn, seeds stored at $4^{\circ} \mathrm{C}$ showed higher GP than those stored at ambient room temperature $\left(\mathrm{ca} .27^{\circ} \mathrm{C}\right)$, and seeds from invasive populations revealed higher GP than those from native populations. The results implied that the high temperature in summer has negative impact on the germination and might cause viability loss or secondary dormancy to $S$. vulgaris seeds. Our study offers a clue to explore what factor limits the distribution of $S$. vulgaris in China by explaining why in the cities in South-East China and central China such as Wuhan S. vulgaris can't establish natural and viable populations. 


\title{
Effects of origin, seasons and storage under different temperatures on germination of
}

\section{Senecio vulgaris L. (Asteraceae) seeds}

\author{
Noel Ndihokubwayo ${ }^{1,2^{*}}$, Nguyen Viet Thang ${ }^{1,3^{*}}$, Dandan Cheng ${ }^{4 * *}$ \\ ${ }^{1}$ School of Environmental Studies, China University of Geosciences (Wuhan), Lumo \\ Road 388, Wuhan, 430074, China \\ ${ }^{2}$ Ecole Normale Supérieure, Département des Sciences Naturelles, Boulevard du 28 \\ Novembre, B.P 6983 Bujumbura, Burundi \\ ${ }^{3}$ Faculty of Biology, Thai Nguyen University of Education, No. 20, Luong Ngoc Quyen \\ Street, Thai Nguyen City, Vietnam
}

${ }^{4}$ State Key Laboratory of Biogeology and Environmental Geology, China University of Geosciences (Wuhan), Lumo Road 388, Wuhan, 430074, China

* Contributed equally to this work.

15

** Correspondence : E-mail : dandan.cheng@cug.edu.cn

\begin{abstract}
Invasive plants colonize new environments, become pests and cause biodiversity loss, economic loss and health damage. Senecio vulgaris L. (Common groundsel, Asteraceae), a cosmopolitan weed wildly distributing in the temperate area, is reported with large populations in the northeastern and south-western part, but not in southern, central, or north-western part of China. We studied the germination behavior of $S$. vulgaris to explain the distribution and the biological invasion of this species in China. We used seeds originating from 6 native and 6 invasive populations to conduct germination experiments in a climate chamber and under outdoor condition. When incubated in a climate chamber $\left(15^{\circ} \mathrm{C}\right)$ seeds from majority of the populations showed $>90 \%$ germination percentage (GP) and the GP was equal for seeds with native and invasive origin. The mean germination time (MGT) was significant different among the populations. Under outdoor conditions, significant effects of origin, storage conditions (stored at $4{ }^{\circ} \mathrm{C}$ or ambient room temperature, ca. $27^{\circ} \mathrm{C}$ ) and seasons (in summer or autumn) were observed on the GP while the MGT was only affected by the season. In autumn, the GP $(38.6 \%)$ was higher and the MGT was slightly longer than that in summer. In autumn, seeds stored at $4{ }^{\circ} \mathrm{C}$ showed higher GP than those stored at ambient room temperature $\left(\right.$ ca. $\left.27^{\circ} \mathrm{C}\right)$, and seeds from invasive populations revealed higher GP than those from native populations. The results implied
\end{abstract}


that the high temperature in summer has negative impact on the germination and might cause viability loss or secondary dormancy to $S$. vulgaris seeds. Our study offers a clue to explore which factor limits the distribution of $S$. vulgaris in China by explaining why in the cities in South-East China and central China such as Wuhan S. vulgaris cannot establish natural and viable populations.

\section{Introduction}

Invasive plants colonize new areas, become pests and cause biodiversity loss, economic loss and health damage (Keller et al., 2011). An invasive species is a non-native species whose introduction does or is likely to cause economic or environmental harm or harm to human, animal, or plant health (Horan \& Lupi, 2010). One of such invasive species is Senecio vulgaris (Common groundsel, Asteraceae) which most probably originated from southern Europe and is widely distributed in the temperate area all over the world (Robinson et al., 2003). Despite the wide distribution of $S$. vulgaris in China, its occurrence is scattered, with large populations reported in the north-eastern and south-western parts, but not in southern, central, northern or north-western part of China (Cheng \& Xu, 2015).

Germination is an important stage in the life cycle of plants and germination behavior limits the distribution. We germinated the seeds in autumn and summer in Wuhan, Central China, where no natural $S$. vulgaris populations are established. In Wuhan, we observed that the plants from seeds germinated in spring ended their life cycle in late spring or early summer, with seed dispersion. Plants from seeds germinated in autumn grew in winter and ended in late spring as well. From this observation, we had a preliminary hypothesis that the $S$. vulgaris seeds cannot germinate, or survive the hot summer in Wuhan. This is the reason why no observable natural $S$. vulgaris populations established in Wuhan and other areas in the north-eastern and southwestern part of China where it is extremely hot in summer.

To test the hypothesis, we collected seeds from various populations from the native range (Europe) and invasive range (China), stored the seeds in different conditions $\left(4^{\circ} \mathrm{C}\right.$ and ambient room temperature, ca. $27^{\circ} \mathrm{C}$ ), and germinated them in a controlled condition $\left(15^{\circ} \mathrm{C}\right)$ and outdoor conditions in summer and autumn in Wuhan. Particularly, we addressed the following questions: (1) Do the storage conditions and seasons have an effect on seed germination? (2) Does the germination behavior vary depending on the origin of range and the populations?

\section{Materials and Methods}

\section{Species description}

Senecio vulgaris is an erect herbaceous annual plant growing up to $45 \mathrm{~cm}$ tall (Stace, 1997), has a thick taproot, and possesses an ephemeral strategy typical of many weedy species (Weiner et al., 2009). S. vulgaris is a ubiquitous weed found in the temperate zones of Europe, North and South America, North Africa and Asia (Robinson et al., 2003). In warmer climates such as 
California, however, it is a winter annual that appears soon after precipitation. Its optimal growing temperature is estimated to be $22^{\circ} \mathrm{C}$ from meristem tips grown in static tube culture (Walkey \& Cooper, 1976). Plants of S. vulgaris develop from seeds annually, and each plant can produce an average of 830 seeds (Kadereit, 1984). But, large plants of $S$. vulgaris can produce over 1700 seeds (Royer \& Dickinson, 1999).

\section{Seeds source}

Seeds from 9 populations of $S$. vulgaris in their native area (Europe) and 7 populations in invasive areas (China) were sampled in different sites in 2012 and 2013, respectively (Table 1). After collection from the field, seeds were kept in paper bags and dried in air. Seed collection occurred between end of May and beginning of October, with most of the seeds collected in June and July (Table 1). Thus, most of the seeds were collected in summer. The plants from which seeds were collected were at least $5 \mathrm{~m}$ from each other within the same population. To avoid the maternal effect, we did not use seeds collected directly from the field.

Seeds of each population were grown for one generation in a climate room $\left(20^{\circ} \mathrm{C}, 18 / 6\right.$ hours, light/dark) in October and November 2013. And one set of seeds collected from these plants grown in climate room was used for the germination experiment in a climate chamber (Product Model: PQX-1000A-12HM, Ningbo Southeast Instrument, CO. LTD, Ningbo, China) in December 2013 and January 2014, 3-4 weeks later after seeds harvesting.

Another set of seeds was germinated and then cultivated in a greenhouse in spring 2014 and harvested on June of the same year. The resulting seeds of the first flowering capitulum were harvested and used in the outdoor germination experiments. From each population, three individual plants that contained a large number of good seeds were selected.

\section{Germination experiment design}

\section{Germination in a climate chamber}

From the 16 populations, we used 6 native and 6 invasive populations for the germination experiment in a climate chamber. Three replications (plants) per population, 10 seeds per plant, and in total 360 seeds were used for this experiment. These seeds did not experience any pretreatment, only were air - dried in paper bags and kept in room temperature in winter (below $\left.20^{\circ} \mathrm{C}\right)$.

The single layer of Whatman No.1 filter paper was placed inside a Petri dish $(9 \mathrm{~cm}$ diameter) and moistened with distilled water. Ten seeds from the same plant were sown on a filter paper. The Petri dishes containing seeds were then placed in a climate chamber (Ningbo Southeast Instrument CO., LTD, Ningbo, China). According to previous work, we selected good conditions for S. vulgaris seed to germinate: temperature was $15^{\circ} \mathrm{C}$, and 12 hours for light (provided by 12 fluorescent tubes) and 12 hours for darkness. Germinated seeds were recorded daily and the test criterion was the protrusion of the radicle. The data collection continued until germination had ceased after 19 days. 
106 Outdoor germination experiments

107 For these experiments, three plants from each of the 6 native and 6 invasive populations were 108 selected, and 40 seeds were chosen from the same individual plant. These 40 selected seeds were 109 kept in two paper bags, 20 seeds in each one. These bags were divided into two lots and each lot 110 consisted of seeds collected from 36 plants representing 12 populations. The lots were then 111 stored under two different temperature conditions: (i) ambient room temperature: seeds in the 112 paper bag were placed in plastic bag containing a bag of silica gel to absorb moisture thereby 113 abating humidity inside the plastic bag and placed in a cardboard box at ambient conditions in 114 the laboratory. The temperature in the laboratory ranged from 20 to $30^{\circ} \mathrm{C}$ and relative humidity 115 was around $70 \%$ during the storage period. (ii) At low temperature: Another lot of seeds was 116 put in plastic bag and tightly sealed and stored in a refrigerator $\left(4^{\circ} \mathrm{C}\right)$. In total 1440 seeds were 117 used in this experiment. The germination experiment was carried out twice, in July and in 118 October. The experiment done in July used seeds stored for one month (seeds harvested in June) 119 while the experiment conducted in October used seeds stored for 4 months.

120 In July (summer) 10 seeds per plant from lots stored at different conditions were sown on a filter paper soaked with tap water in a Petri dish. After sowing, Petri dishes were placed in plastic bags to prevent evaporation and placed in two large opened plastic containers $(65 \times 40 \times 17 \mathrm{~cm})$. The walls of the container were not transparent and each one received 18 Petri dishes. Then, they were placed outdoors where seeds received enough sunlight and daily average temperature ranged from 23 to $32^{\circ} \mathrm{C}$. The Petri dishes were left for $12 \mathrm{~h}$ in the plastic bags and opened for (30) minutes allowing seeds or seedlings to be oxygenated. Tap water was added to keep moist during the experiment. Every morning, the Petri dishes were observed to monitor the number of germinated seeds. Records of daily temperature through the relevant experimental period were obtained from the meteorological office of Wuhan City.

In October (autumn), another germination experiment was done with the seeds from both groups stored in different conditions. These germination experiments and data recording was carried out following the same procedure as in July with a minor modification where the Petri dishes were not wrapped in plastic bags, because the temperature usually was below $30^{\circ} \mathrm{C}$ during that period.

\section{Germination parameters}

135 Two germination characteristics which are germination percentage (GP) and mean germination

136 time (MGT) were estimated. MGT was determined according to the equation of Ellis \& Roberts 137 (1980): MGT $=\sum \mathrm{dn} / \sum \mathrm{n}$, where $\mathrm{n}$ is the number of seeds newly germinated on days $\mathrm{d}$, $\mathrm{d}$ refers as days counted from the beginning of germination test, and $\sum \mathrm{n}$ is the total seeds germinated.

\section{Data analysis}

140 A two level nested-ANOVA was performed for the data from the experiment conducted in a 141 climate chamber to assess whether the difference in GP and MGT was significant between 142 distribution range and populations within the range. Multiple comparisons by means of Tukey 
143 Contrasts was conducted to figure out which populations were significantly different from others

144 in relation to MGT.

145 The results of one-way ANOVA tests indicated that there were generally no significant

146 difference of GP and MGT among the populations within the same range, storage under the same

147 condition and germinated in the same season (Table S1). Therefore, three-way ANOVA was

148 used to determine significant differences in GP and MGT due to ranges, storage conditions and

149 seasons on seed germination. To show the effect of every factor clearly, data were divided into

150 groups according to the combination of two factors and t-tests were conducted to compare each

151 couple defined by the third factor in different groups.

152 Before statistical analysis, the germination parameters (GP and MGT) were log-transformed to 153 get distribution normality. Breusch-Pagan test was used to check homoscedasticity and

154 Bonferonni outlier test was used for data - normality checking.

155 All statistical methods were performed using R software, version 3.2.1(R Core Team, 2015).

156

157

158

159

160

161

162

163

164

165

166

167

168

169

170

171

172

173

174

175

176

177

\section{Results}

\section{Germination experiment in the climate chamber}

The $S$. vulgaris seeds started to germinate at the 4th and 5 th day after sowing for invasive and native populations, respectively. A high germination took place between the 4 th and the 16 th day (Figure1). After 19 days of germination experiment, all populations had $>80 \%$ of GP and 8 of the 12 populations had $\geq 90 \%$ GP (Figure 2 ). The final GP (91.1\%) was the same for invasive and native populations (Figure 1). In addition, there was no significant difference in GP between the ranges and the populations within the ranges (two - level nested ANOVA, $\mathrm{df}=1$ and 10, P> $0.05)$.

The mean germination time (MGT) was not statistically different between the ranges, however, within the ranges, the populations were significantly different (two - level nested ANOVA, $\mathrm{df}=1$ and 10 , for range: $\mathrm{F}=0.631$, for populations within range: $\mathrm{F}=2.398, \mathrm{P}=0.039$ ). The highest value of the MGT (13.51 days) was found in population from Tongjiang which belongs to the invasive range while the lowest value (7 days) was recorded in population from Oegstgeest that belongs to native range. Populations from Oegstgeest and Tongjiang were significantly different from each other, and these two populations significantly differ from the other 10 populations (Figure 2).

\section{Outdoor germination experiments}

Compared to the seeds germinated in summer, the GP of the seeds germinated in autumn was much higher, no matter which range the seeds from or under what kind of conditions the seeds were stored (Figure 3a, Figure 4a). GP of $S$. vulgaris seeds were significantly different between the seasons (S), storage conditions $(\mathrm{SC})$ and ranges $(\mathrm{R})$. Only the interaction of $\mathrm{SC} \times \mathrm{S}$ was 
178 significant (Table 2). The influence of range and storage conditions on the GP depends on 179 seasons.

180 In autumn, GP of the seeds from invasive range was significantly higher than that from native 181 range, no matter under what kind of conditions the seeds were stored. In summer, there was no 182 difference between invasive and native seeds in relation to GP (Figure 4b). In autumn, final GP 183 of seeds stored under $4^{\circ} \mathrm{C}$ was $54.17 \%$, and final GP of those stored under $27^{\circ} \mathrm{C}$ was $22.78 \%$,

184 while the GP of the seeds germinated in summer was no more than $5 \%$ and was not different 185 between the seeds stored under different conditions (Figure 4c).

186 The $S$. vulgaris seeds started to germinate at the $2^{\text {nd }}$ day after sowing in autumn, and in summer 187 they started germination at the $5^{\text {th }}$ day. Most germination in autumn took place between the $2^{\text {nd }}$ 188 and $8^{\text {th }}$ day after sowing. MGT for the two seasons (summer and autumn) was statistically 189 different and no interaction was revealed to be significant (Table 2). Higher MGT was recorded 190 in autumn for both ranges and both storage conditions than in summer.

Discussion

Do seasons and storage conditions have effect on seed germination of $S$. vulgaris? Our result showed a high GP $(91.51 \%)$ at constant temperature of $15^{\circ} \mathrm{C}$, indicating that the temperature conditions $\left(15^{\circ} \mathrm{C}\right)$ are appropriate or situated closer to the optimum germination temperature for $S$. vulgaris seeds. In summer, the GP was very low (4.5\%), compared to that of autumn $(38.6 \%)$. This could be due to the high temperature during the experimental period in summer when the average temperature ranged from 25 to $30^{\circ} \mathrm{C}$, and the maximum temperature ranged from 27 to $37^{\circ} \mathrm{C}$ (Figure $3 \mathrm{c}$ ). Our results agree with previous studies that reported the optimum growing or germination temperature for $S$. vulgaris ranging between $10^{\circ} \mathrm{C}$ and $25^{\circ} \mathrm{C}$, above or beyond these limits, the GP declines (Popay \& Roberts, 1970a; Ren \& Abbott, 1991; Walkey \& Cooper, 1976).

In autumn, seeds stored at $4^{\circ} \mathrm{C}$ displayed higher GP than those stored at ambient room temperature (Figure 4c). The reason for this might be that seeds stored at room temperature from July to October were subjected to the variation in temperature (Figure S1) and humidity that is high in summer, and resulting in a loss of viability, or secondary dormancy. Popay \& Roberts (1970b) found that dry S. vulgaris seeds at high temperature 35 for 10 weeks got high GP at germination seeds, but some previous studies showed that storage at room temperature often resulted in low seed germination (Nasreen et al., 2000). Hence, it is interesting to confirm what is the real reason by further experiments.

210 Do GP and MGT of $\boldsymbol{S}$. vulgaris seeds vary depending on their origination?

211 In climate chamber at $15^{\circ} \mathrm{C}$, the MGT was different between populations, implying that the 212 origin might influence the speed of seed germination. However, there was no difference in GP 
213 between the ranges, or between populations within the range. Under this optimum germination

214 condition and after a rather long period (19 days), every S. vulgaris seed with good quality could

215 germinate. This might be the reason why we did not found different final GP between

216 populations and ranges.

217 In the outdoor experiment during autumn, the GP was statistically different between the ranges

218 (Table 2, Figure 4b). We also found, in autumn, the seeds stored at $4{ }^{\circ} \mathrm{C}$ and from invasive plants

219 gained about $65 \%$ GP, those from native plants gained about $45 \%$; and the difference of GP

220 between the range was significant (Table 2, Figure $4 \mathrm{~b}$ ). The high germination in invasive

221 populations may be due to their ability to thrive in the new environment, probably based on the

222 rapid adaptation or their genotype evolution as it was reported for many species (Hierro et al.,

223 2009; Skálová et al., 2011; Leiblein-Wild et al., 2014).

224 Additionally, $S$. vulgaris has a wide distribution range (Holm et al., 1979) which means that the

225 geographical variation may lead to the difference in germination behavior as it was detected in

226 other species (Lindauer \& Quinn, 1972; Thompson, 1975). Our results are consistent with

227 previous studies carried out with $S$. vulgaris seeds collected from different areas such as Scotland

228 and South Spain (Ren \& Abbott, 1991); Kentucky and Michigan (Figueroa et al., 2010);

229 Scotland and Yugoslavia (Richards, 1975). The present results showed that the germination

230 behavior occurred differently according to the geographic origin of the seeds.

\section{Conclusions}

232 We observed that seeds of $S$. vulgaris could germinated in short time after sowing and had high

$233 \mathrm{GP}$ at $15^{\circ} \mathrm{C}$ in a climate chamber and in an outdoor germination experiment in autumn. Low GP

234 observed for seeds germinated in summer and seeds kept at ambient room temperature (about

$23527^{\circ} \mathrm{C}$ ). This indicated that high temperature in summer has negative impact on the germination

236 and might cause viability lost or secondary dormancy to of $S$. vulgaris seeds. The present results

237 showed that the germination behavior occurred differently according to the geographic origin of

238 the seeds. We found that seeds from invasive plants gained high GP than those from native ones

239 in the outdoor experiment during autumn. This indicated that the invasive $S$. vulgaris could be

240 more adapted to some environments in China. Our study offers a clue to explore which factor

241 limits the distribution of $S$. vulgaris in some regions of China by explaining why in the cities in

242 South-East China and central China such as Wuhan S. vulgaris cannot establish natural and

243 viable populations.

\section{Acknowledgment}

245 Colleagues in the School of Environmental Studies at China University of Geosciences (Wuhan)

246 and Institution of Biology in Leiden University are thanked for helping in seed collection. We

247 further acknowledge Harold W.T. Mapoma, Prosper Laari and Tananga M. Nyirenda for their 
248 valuable comments on the manuscript. The two anonymous reviewers should receive our

249 warmest gratitude for their invaluable comments that significantly improved this paper. 
251

252

253

254

255

256

257

258

259

260

261

262

263

264

265

266

267

268

269

270

271

272

273

274

275

276

277

278

279

280

281

282

283

284

285

286

287

288

289

290

291

292

293

294

295

\section{References:}

Cheng D, and Xu L. 2015. Predicting the potential distributions of Senecio vulgaris L. in China.PeerJ PrePrints 3:e1612v1 https://doi.org/10.7287/peerj.preprints.1612v1

Ellis RH, and Roberts EH. 1980. Improved equations for the prediction of seed longevity. Annal of Botany 45:13-30.

Figueroa R, Herms DA, Cardina J, and Doohan D. 2010. Maternal Environment Effects on Common Groundsel (Senecio vulgaris) Seed Dormancy. Weed Science 58:160-166.

Hierro JL, Eren O, Khetsuriani L, Diaconu A, Torok K, Montesinos D, Andonian K, Kikodze D, Janoian L, Villarreal D, Estanga-Mollica ME, and Callaway RM. 2009. Germination responses of an invasive species in native and non-native ranges. Oikos 118:529-538

Holm LG, Pancho JV, Herberger JP, and Plucknett DL. 1979. A geographical atlas of world weeds. New York: John Wiley and Sons.

Horan RD, and Lupi F. 2010. The economics of invasive species control and management: The complex road ahead. Resource and Energy Economics 32:477-482.

Kadereit JW. 1984. Studies on the biology of Senecio vulgaris L. ssp. denticulatus (O.F. Muell.) .D. Sell. . New Phytologist 97:681-689.

Keller RP, Geist J, Jeschke JM, and Kühn I. 2011. Invasive species in Europe: ecology, status, and policy. Environmental Sciences Europe 23:1-17.

Leiblein-Wild MC, Kaviani R, and Tackenberg O. 2014. Germination and seedling frost tolerance differ between the native and invasive range in common ragweed. Oecologia 174:739-750

Lindauer LL, and Quinn JA. 1972. Germination ecology of Danthonia sericea populations. American Journal of Botany 59: 942-951.

Nasreen S, Khan BR, and Mohmad AS. 2000. The effect of storage temperature, storage period and seed moisture content on seed viability of soya bean. Pakistan Journal of Biological Science 3:2003-2004.

Popay A, and Roberts E. 1970a. Factors involved in the dormancy and germination of Capsella bursa-pastoris (L.) Medik. and Senecio vulgaris L. Journal of Ecology 58:103-122.

Popay AI, and Roberts EH. 1970b. Ecology of Capsella bursa-pastoris (L.) Medic, and Senecio vulgaris L. in relation to germination behaviour. Journal of Ecology 58:123-139

Ren Z, and Abbott RJ. 1991. Seed dormancy in Mediterranean Senecio vulgars L. New Phytologist 117:673-678.

Richards AJ. 1975. The inheritance and behaviour of the rayed gene complex in Senecio vulgaris. Heredity 34: 95-104.

Robinson DE, O'Donovan JT, Sharma MP, Doohan DJ, and Figueroa R. 2003. The biology of Canadian weeds. 123. Senecio vulgaris L. Canadian Journal of Plant Science 83: 629644.

Royer F, and Dickinson R. 1999. Weeds of the Northern U.S. and Canada: A Guide for Identification. Edmonton: The University of Alberta Press.

Skálová H, Moravcová L, and Pyšek P. 2011. Germination dynamics and seedling frost resistance of invasive and native Impatiens species reflect local climatic conditions. Perspectives in Plant Ecology, Evolution and Systematics 13:173- 180.

Stace CA. 1997. New flora of the British isles (2nd ed.). Cambridge: Cambridge University Press. 
296

297

298

299

300

301

302

303

304

305
R Core Team. 2015. R: A language and environment for statistical computing. R Foundation for Statistical Computing, Vienna, Austria.

Thompson PA. 1975. Characterisation of the germination responses of Silene dioica (L.)

Clairv., populations from Europe. Annal of Botany 39:1-19.

Walkey DGA, and Cooper J. 1976. Growth of Stellaria media, Capsella bursa-pastoris and Senecio vulgaris plantlets from cultured meristem-tips. Plant Science Letters 7:179-186.

Weiner J, Rosenmeier L, Massoni ES, Vera JN, Plaza EH, and Sebastià MT. 2009. Is reproductive allocation in Senecio vulgaris plastic? Botany 87:475-481. 


\section{Table 1 (on next page)}

Origin of the populations of Senecio vulgaris used in this study. 


\begin{tabular}{llllll}
\hline Range & Country & Location & Collected time & Latitude & Longitude \\
\hline Native & Spain & Barcelona $^{2}$ & June,2012 & 41.67 & 2.73 \\
Native & Switzerland & Fribourg $^{2}$ & July,2012 & 46.79 & 7.15 \\
Native & The Netherlands & Leiden $^{1,2}$ & Oct, 2013 & 52.17 & 4.48 \\
Native & The Netherlands & Lisse $^{1}$ & May, 2012 & 52.25 & 4.55 \\
Native & The Netherlands & Oegstgeest $^{1,2}$ & Oct, 2013 & 52.11 & 4.28 \\
Native & Germany & Potsdam $^{1}$ & July, 2012 & 52.39 & 13.06 \\
Native & Poland & Pulawy $^{2}$ & July, 2012 & 51.39 & 21.96 \\
Native & United Kingdom & St Andrew $^{1,2}$ & May, 2012 & 56.33 & -2.78 \\
Native & The Netherlands & Teylingen $^{1}$ & Oct, 2013 & 52.21 & 4.49 \\
Invasive & China & Fuyuan $^{1,2}$ & July, 2013 & 48.37 & 134.29 \\
Invasive & China & Hegang $^{1,2}$ & July, 2013 & 47.33 & 130.29 \\
Invasive & China & Lijiang $^{1,2}$ & Sept, 2013 & 26.87 & 100.24 \\
Invasive & China & Luobei $^{1}$ & July, 2013 & 47.57 & 130.82 \\
Invasive & China & Siping $^{1,2}$ & July, 2013 & 43.17 & 124.38 \\
Invasive & China & Tongjiang $^{1,2}$ & July, 2013 & 47.98 & 133.17 \\
Invasive & China & Yichun $^{2}$ & July, 2013 & 47.72 & 128.79 \\
\hline
\end{tabular}

1

2 1: populations used in the germination experiment in a climate chamber

3 2: populations used in outdoor germination experiments

4

5

6

7

8

9 


\section{Table 2 (on next page)}

Analysis of variance of final germination percentage (GP, \%) and mean germination time (MGT, days) for Senecio vulgaris seeds from 6 native and 6 invasive populations.

Seeds were stored under different conditions (at $4{ }^{\circ} \mathrm{C}$ and ambient room temperature, ca. 27 ${ }^{\circ} \mathrm{C}$ ) and germinated in different seasons (summer and autumn). 


\begin{tabular}{llll}
\hline Source of variation & & GP & MGT \\
\cline { 2 - 4 } & df & F & F \\
\cline { 2 - 4 } Range $(\mathrm{R})$ & 1 & $10.0804^{* *}$ & 3.1723 \\
Storage condition $(\mathrm{SC})$ & 1 & $6.7871^{*}$ & 0.5177 \\
Season (S) & 1 & $117.2067^{* * *}$ & $38.0943^{* * *}$ \\
$\mathrm{R} \times \mathrm{SC}$ & 1 & 0.18 & 0.005 \\
$\mathrm{R} \times \mathrm{S}$ & 1 & $3.9866^{*}$ & 0.0523 \\
$\mathrm{SC} \times \mathrm{S}$ & 1 & $6.3788^{*}$ & 0.1391 \\
$\mathrm{R} \times \mathrm{SC} \times \mathrm{S}$ & 1 & 0.0033 & 0.0071 \\
\hline
\end{tabular}

1 Significance codes: ${ }^{* * *} \mathrm{P}<0.001 ;{ }^{*} \mathrm{P}<0.01 ;{ }^{*} \mathrm{P}<0.05$. 


\section{Figure 1 (on next page)}

Cumulative germination percentage of Senecio vulgaris seeds form 6 native and 6 invasive populations in a climate chamber $\left(15^{\circ} \mathrm{C}, 12 \mathrm{~h} / 12 \mathrm{~h}\right.$, dark/light) during 19 days.

- seeds from the invasive populations; seeds from the native populations. Ten seeds per each of 3 plants from each of the populations were used in this experiment. 


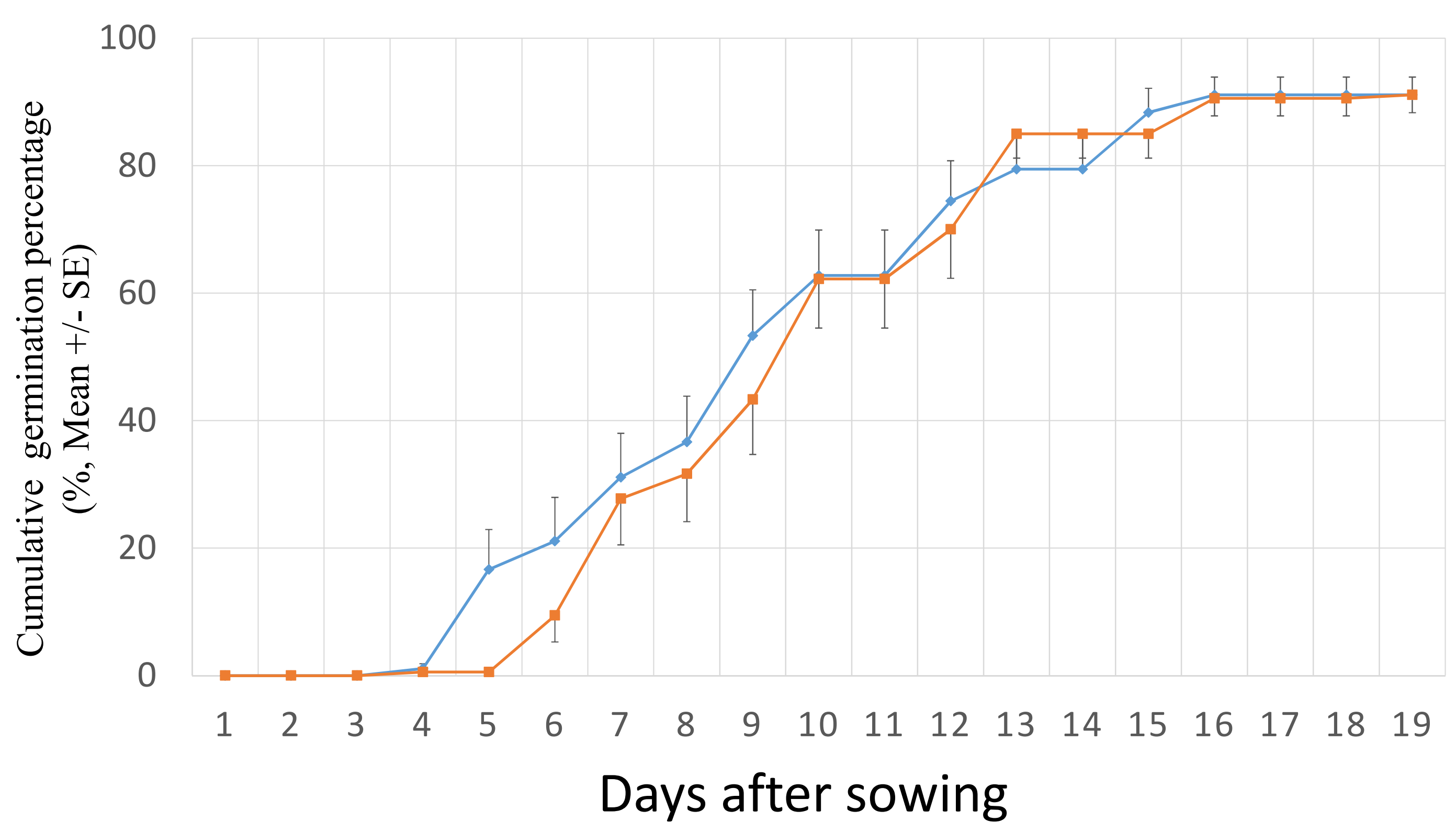


Figure 2 (on next page)

Final germination percentage (GP, bars) and mean germination time (MGT, dots) for Senecio vulgaris seeds from 6 native and 6 invasive populations in a climate chamber during 19 days.

The condition in the climate chamber was: $15{ }^{\circ} \mathrm{C}, 12 \mathrm{~h} / 12 \mathrm{~h}$, dark/light. Ten seeds per each of 3 plants from each of the populations were used in this experiment. No significant difference in GP was found between the ranges and the populations within the ranges. MGT was not statistically different between the ranges. Letters above the dots represent the results of multiple comparisons between populations in relation to MGT. 


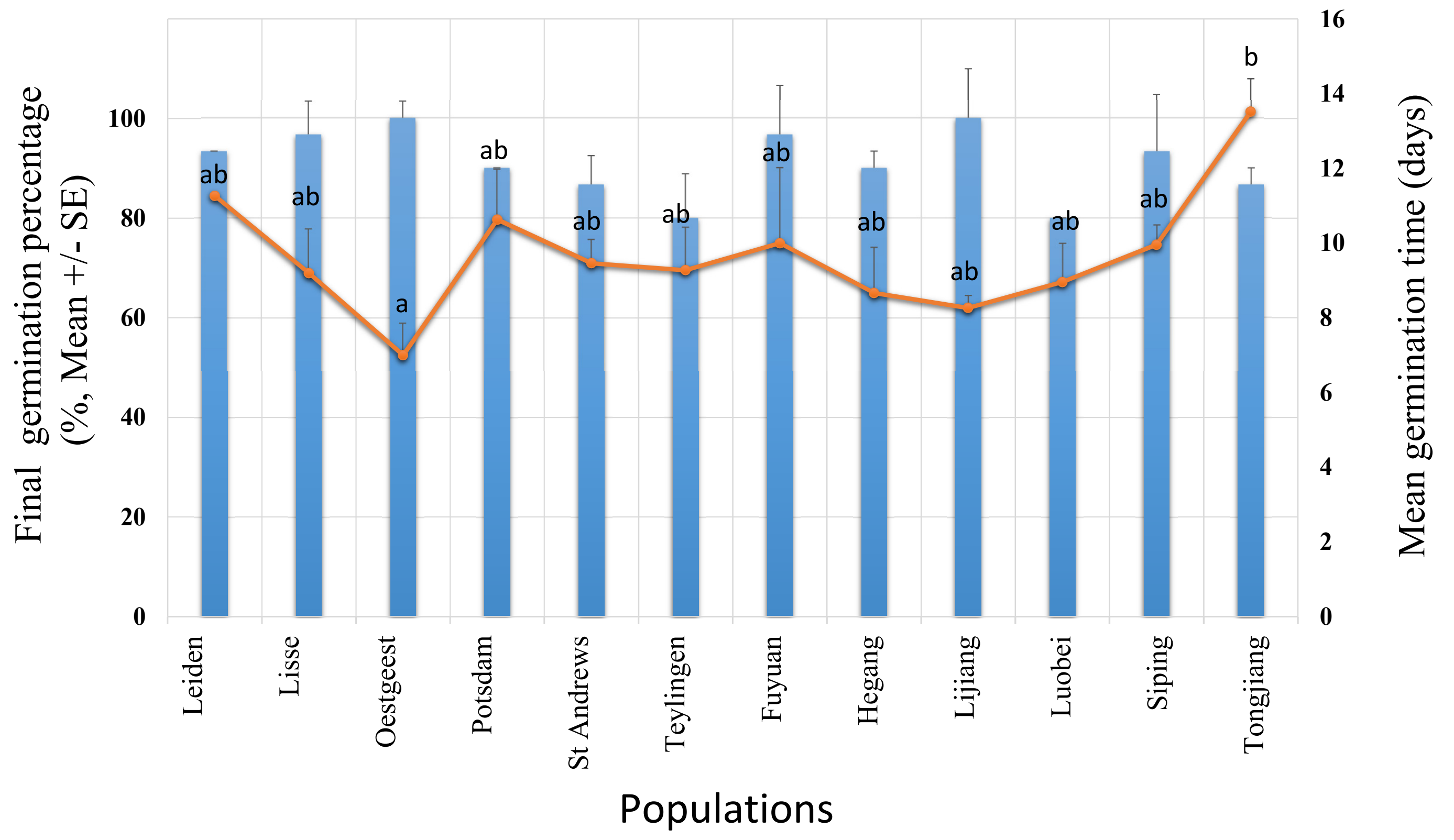




\section{Figure 3 (on next page)}

Cumulative germination percentage (GP) of Senecio vulgaris seeds and daily temperature during the experimental period.

a-b: Cumulative GP of Senecio vulgaris seeds from 6 native and 6 invasive populations in an outdoor germination experiment during summer (a) and autumn (b) ( seeds stored at ambient room temperature, ca. $27^{\circ} \mathrm{C}$; seeds stored at $4^{\circ} \mathrm{C}$; seeds used in summer and autumn were stored for one month and four month, respectively). c-d: Daily max ( $\bullet$ ), min ( $\mathbf{\square}$ ) and mean ( $\mathbf{\Lambda})$ temperature during the experiment in summer (c) and in autumn (d). Data of temperature throughout the relevant experimental period were obtained from the meteorological office of Wuhan City. 

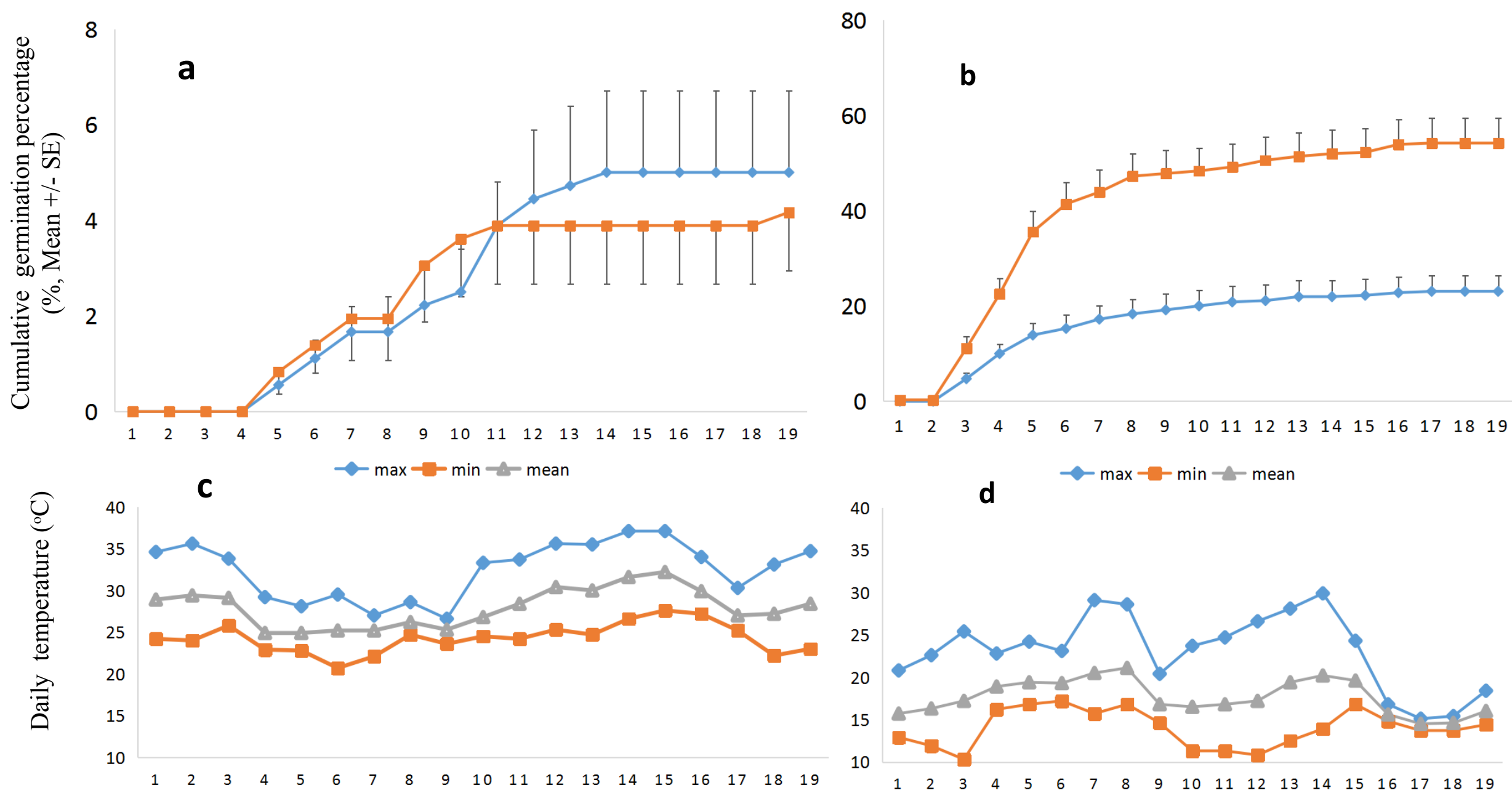

Days after sowing

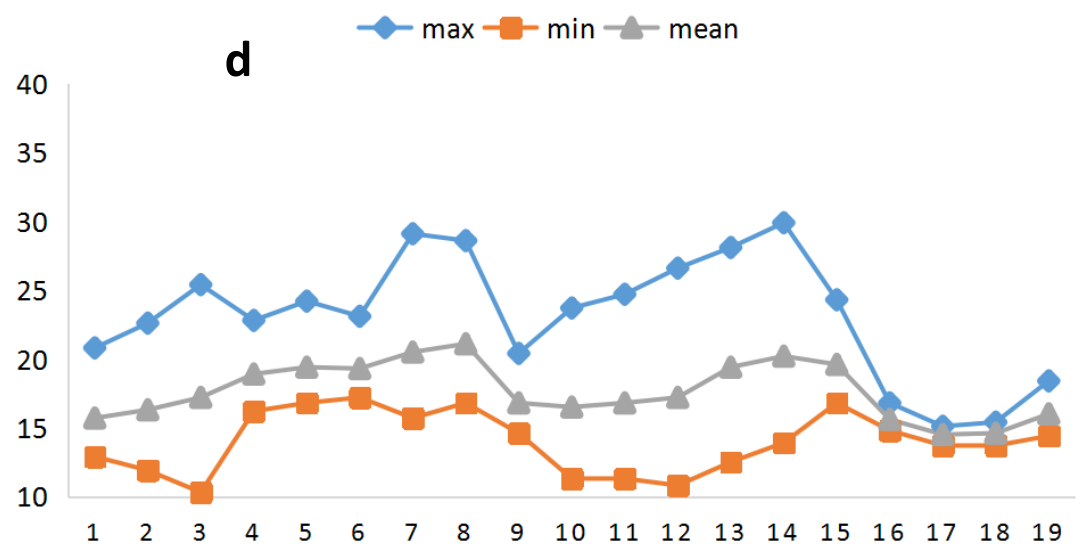

Days after sowing 


\section{Figure 4 (on next page)}

Comparison of the final germination percentage (GP) of Senecio vulgaris seeds germinated in different seasons, from different ranges and stored under different conditions.

a: Comparison of final GP of seeds germinated in autumn and summer in 4 different groups divided according to the ranges and storage conditions (at $4{ }^{\circ} \mathrm{C}$ and ambient room temperature, ca. $27{ }^{\circ} \mathrm{C}$ ); b: Comparison of GP of seeds from native and invasive ranges in 4 different groups divided according to different storage conditions (at $4{ }^{\circ} \mathrm{C}$ and ambient room temperature, ca. $27^{\circ} \mathrm{C}$ ) and germinating seasons (summer and autumn); c: Comparison of GP of seeds stored under different conditions in 4 different groups divided according to the ranges and germinating seasons. 
a

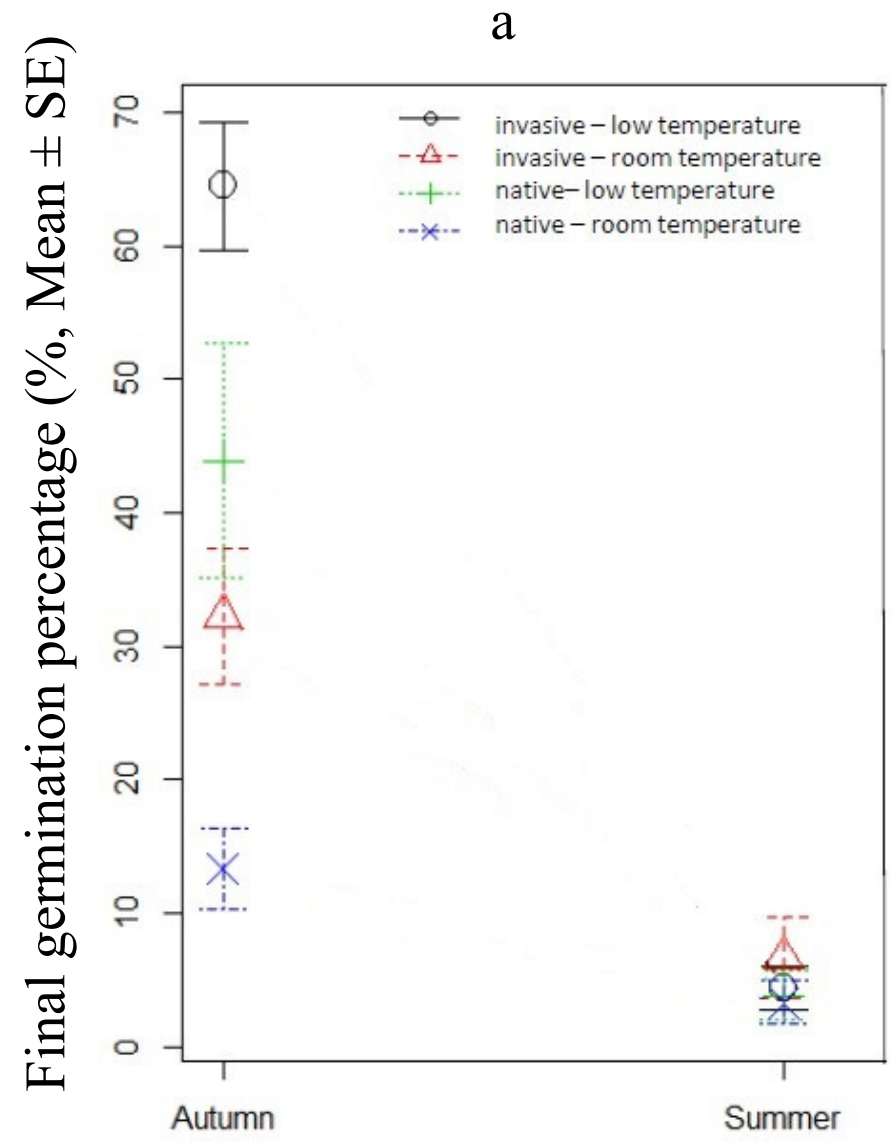

b

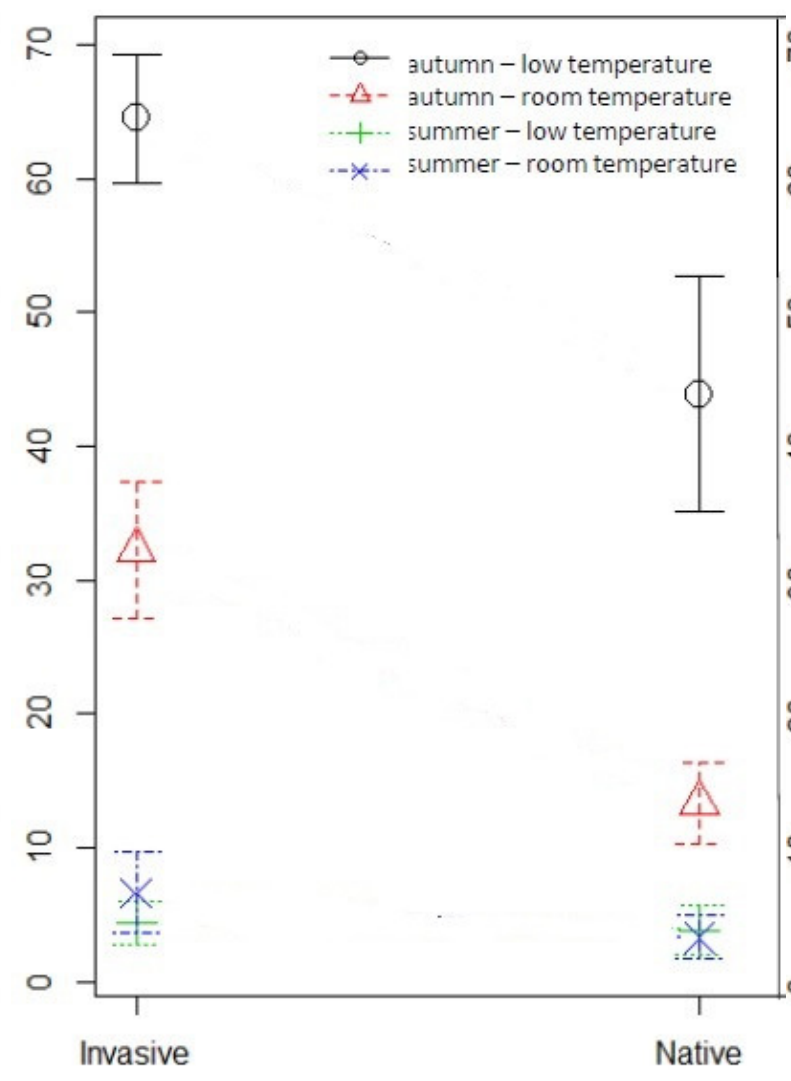

C

- - invasive-autumn invasive-summer native-autumn native-summer 